\title{
Structural Study of Methylated and Non-Methylated Duplexes by IR Fourier Spectroscopy
}

\author{
V. G. Kunitsyn, P. A. Kuznetsov, E. N. Demchenko, O. I. Gimautdinova \\ Scientific Research Institute of Biochemistry, SD RAMS, Novosibirsk, Russia \\ Email: kunitsyn41@mail.ru, pawelkuzn@mail.ru
}

Received 15 July 2015; accepted 15 August 2015; published 18 August 2015

Copyright (C) 2015 by authors and Scientific Research Publishing Inc.

This work is licensed under the Creative Commons Attribution International License (CC BY).

http://creativecommons.org/licenses/by/4.0/

(c) (†) Open Access

\begin{abstract}
Structure of the duplex consisting of 23 pairs of bases was studied before and after the methylation of two cytosine molecules from different chains of the duplex. The study was performed in a buffer solution using an IR Fourier spectrometer. The absorption bands corresponding to the duplex backbone were found to change their characteristics after the methylation. Firstly, the integrated intensity ratio of the absorption bands, $S_{1044} / S_{1085}$, decreased by a factor of 1.5 . The absorption band at $1044 \mathrm{~cm}^{-1}$ corresponds to the COC bond of deoxyribose, and the band at 1085 $\mathrm{cm}^{-1}$ to the $\mathrm{PO}_{2 \text { symm.vibr }}$ bond. Secondly, a substantial shift of the absorption band $1085 \rightarrow 1112 \mathrm{~cm}^{-1}$ $\left(\Delta v=27 \mathrm{~cm}^{-1}\right)$ was observed. In addition, pronounced changes in the absorption region of $\mathrm{CH}$ stretching vibrations took place. In particular, shifting of some absorption bands assigned to the stretching vibrations of $\mathrm{CH}$ bonds; the $2979 \rightarrow 2945.7 \mathrm{shift}$ was equal to $33.3 \mathrm{~cm}^{-1}$. In addition to the indicated changes, some bands corresponding to the $\mathrm{Z}$ structure appeared in the methylated duplex. Thus, methylation of two cytosine molecules in the duplex leads to the order $\rightarrow$ order structural transition, most likely to the $\mathrm{B} \rightarrow \mathrm{Z}$ transition.
\end{abstract}

\section{Keywords}

Duplex, Duplm, Structural Study, FTIR Spectroscopy

\section{Introduction}

CpG islands in native DNA are known to exist mainly in the methylated form [1]. The methylation of DNA controls all genetic processes and serves as the mechanism of cell differentiation and gene repression [2] [3]. In some works, (CCGCC $)_{\mathrm{n}}$ duplexes were studied by IR Fourier spectroscopy. Consecutive methylation of the 
duplex produced determinate changes in the region of $820-840 \mathrm{~cm}^{-1}$. The observed bands were attributed to the $\mathrm{B}$-structure and $\mathrm{BI} \rightarrow \mathrm{BII}$ structural transitions [4]. On the other hand, investigation of molecular dynamics in the methylated $(\mathrm{CCGCC})_{\mathrm{n}}$ duplex predicted the appearance of $\mathrm{B} \rightarrow \mathrm{Z}$ transition [5]. Quite interesting is the IR Fourier spectroscopy study of $(C C G C C)_{n}$ duplex in dependence on temperature in the range of $200-290 \mathrm{~K}$. The $\mathrm{B} \rightarrow \mathrm{Z}$ and $\mathrm{ZI} \rightarrow \mathrm{ZII}$ transitions were revealed in the indicated temperature region [6]. Methylated (CCGCC $)_{\mathrm{n}}$ duplexes are certainly of great interest [2] [3]. However, we think that investigation of the minimally methylated duplexes with a single CCGCC site in the AT enriched nucleotide environment is also important. The model system was represented by oligo-deoxyribonucleotide duplex consisting of 23 pairs of bases, which had a single (GCNGC) site simulating the binding site of THC-apoA-I complex on native DNA and oligonucleotides [7]-[9]. Prior to examining the interaction of methylated duplex with THC-apoA-I complex, we studied the structure of the duplex by IR Fourier spectroscopy. The goal of the work was to investigate structural changes of methylated duplex using IR Fourier spectroscopy.

\section{Materials and Methods}

\section{Deoxyribooligonucleotides:}

I) 5'-GAGTTTAGCGGCTATCGATCTCT-3' and II) 5'-AGAGATCGATAGCCGCTAAACTC-3' were synthesized at the Institute of Chemical Biology and Fundamental Medicine SB RAS (Novosibirsk).

The $\left[\gamma_{-}{ }^{32} \mathrm{P}\right]$ ATP tracer (Isotope, St. Petersburg, $1 \mathrm{Ci} / \mathrm{mol}$ ) was introduced to the 5 '-end of oligonucleotides using polynucleotide kinase of T4 bacteriophage (SibEnzyme, Novosibirsk).

The OLI/OLII duplex was obtained by annealing of initial oligonucleotides taken in equimolar ratio $\left(90^{\circ} \mathrm{C}, 3\right.$ min, gradual cooling to room temperature).

Methylation of the duplex catalyzed by M. Fsp4HI methyltransferase (SibEnzyme, Novosibirsk) was carried out according to the analytical certificate of the enzyme: $1.7 \times 10^{-8} \mathrm{M}$ of the OLI/OLII duplex, $80 \mu \mathrm{M}$ of SAM, 1 a.u. of methyltransferase M. Fsp4HI in a methylation buffer $\left(10 \mathrm{mM}\right.$ Tris-HCl, pH 7.6, $10 \mathrm{mM} \mathrm{MgCl}_{2}, 1 \mathrm{mM}$ DTT). The mixture was incubated at $30^{\circ} \mathrm{C}$ for $1 \mathrm{~h}$. Methylation of the duplex involved cytosine from each nucleotide sequence to obtain one molecule of methylated cytosineper one oligonucleotide sequence. The reaction was stopped by adding $1 \mu \mathrm{l}$ of $0.5 \mathrm{~m}$ EDTA [10].

IR Fourier Spectra. Spectra of the duplexes were recorded in a Fourier spectrometer (Nicolet 6700, Thermo Scientific) using the Frustrated Total Internal Reflection (FTIR) method with a diamond cell at a resolution of 4 $\mathrm{cm}^{-1}$ in the frequency range of $900-4000 \mathrm{~cm}^{-1}$, in isotonic Tris buffer with the addition of $\mathrm{K}$, Na salts (pH 7.4). Volume of the tested solution was $6.0 \mu \mathrm{l}$. A sample was covered with a fluoroplastic cap, which was pressed to the cell. The optical chamber was sealed and purged with dry air. The time of spectra recording ranged from 30 $\mathrm{s}$ to $1 \mathrm{~min}$. Mathematical treatment of the spectra was performed using a special OMNIC software attached to the spectrometer.

\section{Results}

IR Fourier spectra. Analysis of the spectra revealed the absorption bands at 1085.67 (the $\mathrm{PO}_{2}$ bond) and 1044.44 (the $\mathrm{C}_{4}-\mathrm{O}_{4}-\mathrm{C}_{5}-\mathrm{O}_{5}$ bond) [8] [9] for the duplex (dupl_23) and 1112.56 and $1044.31 \mathrm{~cm}^{-1}$ bands for the methylated duplex (duplm_23) (Figure 1(a) and Figure 2(a)). It is seen that the absorption band of the $\mathrm{PO}_{2}$ bond in duplm_23 is shifted to the short-wave region by $26.89 \mathrm{~cm}^{-1}$. In addition, the integrated intensity ratio $\mathrm{S}_{1044.44} / \mathrm{S}_{1085.67}$ was equal to 4.38 in the duplex, while in duplm_23 the $\mathrm{S}_{1044.31} / \mathrm{S}_{1112.56}$ ratio was 2.82 (Table 1). Thus, the first value is greater than the second one by a factor of 1.55. A substantial shift of the absorption band of $\mathrm{PO}_{2}$ bond to the short-wave region and changes in the ratio of the indicated bands testify to the conformational changes in the backbone that occur due to methylation of bases (cytosine). The methylation involved only two bases residing in different oligonucleotide chains, while the backbone changed only slightly. This suggests the effect of hyperconjugation of the methyl group with the base [11], which produces radical changes in the electron distribution and order of the bonds in bases and side radicals, and hence leads to conformational changes in the backbone and the entire molecule. The absorption bands at 1199.17 and $1218.25 \mathrm{~cm}^{-1}$ (dupl_23) as well as 1213.03 and $1230.93 \mathrm{~cm}^{-1}$ (duplm_23) can be attributed to the $\mathrm{P}=\mathrm{O}$ bonds [8] [9] (Figure 1 and Figure 2). In this case, a $12-14 \mathrm{~cm}^{-1}$ shift to the short-wave region is also observed. The indicated changes suggest that the pitch of a helix decreases due to an increased ordering of bases and a stronger Van der Waals interaction between them. In this case, of special interest in the analysis of CH bonds. In dupl_23, deformation vibrations of 
Therrno Fisher SCIENTIFIC

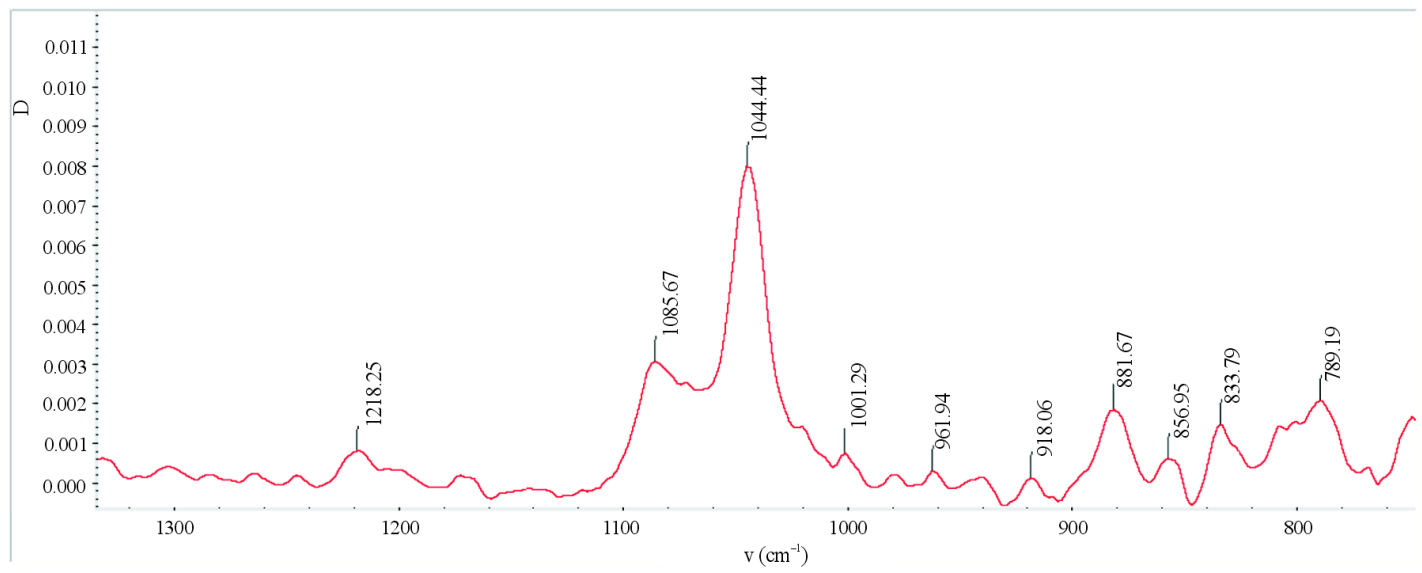

(a)

Therrno Fisher

S C IEN T IF IC

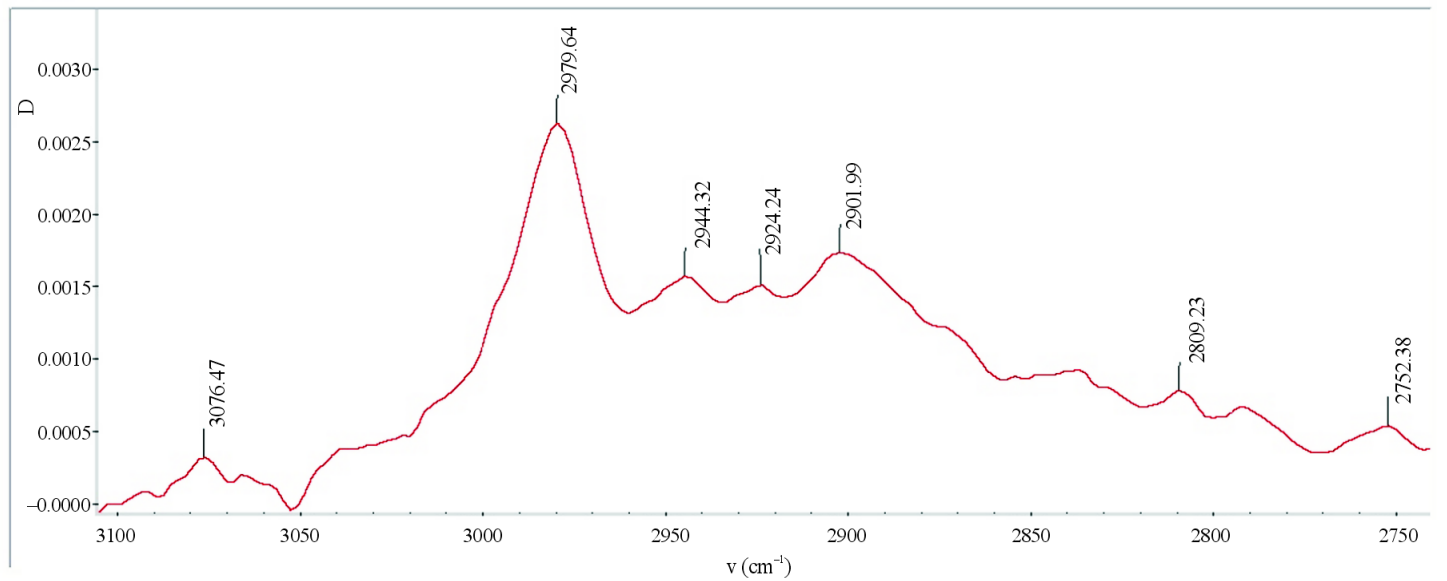

(b)

Figure 1. (a) FTIR spectra of dupl.: $\left(\mathrm{C}_{\text {tris-HClbuf }}=0.01 \mathrm{M}, \mathrm{pH} 7.4\right) ; v=800-1300 \mathrm{~cm}^{-1}$; (b) FTIR spectra of dupl.: $\left(\mathrm{C}_{\text {tris-HClbuf }}\right.$ $=0.01 \mathrm{M}, \mathrm{pH} 7.4) ; v=2700-3100 \mathrm{~cm}^{-1}$.

Table 1. Frequency characteristics of the FTIR spectra of methylated (duplm) and non-methylated (dupl) duplexes.

\begin{tabular}{|c|c|c|c|c|c|c|c|c|c|}
\hline No. & Compound & $\mathrm{NH}_{\text {def. }}$ & $\mathrm{CH}_{\text {def. }}$ & $\mathrm{CH}_{3}$ & $\mathrm{CH}_{\text {stretch. }}$ & $\begin{array}{c}\mathrm{P}=\mathrm{O} \\
\text { assym.vibr. }\end{array}$ & $\begin{array}{c}\mathrm{PO}_{2} \\
\text { symm.vibr. }\end{array}$ & $\begin{array}{c}\text { C-O-C } \\
\text { deoxyrib }\end{array}$ & $\begin{array}{c}\text { C-C } \\
\text { deoxyrib }\end{array}$ \\
\hline \multirow{6}{*}{1.} & \multirow{4}{*}{ Dupl } & 1530 & 1450.9 & \multirow[t]{4}{*}{1335.3} & 3049 & 1271.2 & \multirow[t]{4}{*}{1087.3} & \multirow[t]{4}{*}{1045.1} & \multirow[t]{4}{*}{970.1} \\
\hline & & & 1421 & & 2981.8 & 1222.9 & & & \\
\hline & & & & & 2925.3 & & & & \\
\hline & & & & & 2903.2 & & & & \\
\hline & & - & 0.0008 & 0.0005 & & 0.0005 & 0.0012 & 0.0069 & 0.0003 \\
\hline & Intensity & 0.0021 & & & & 0.0007 & & & \\
\hline \multirow{6}{*}{2.} & \multirow{3}{*}{ Duplm } & \multirow[t]{3}{*}{1538.9} & 1459.2 & \multirow[t]{3}{*}{1337.2} & 3063.3 & 1280.8 & \multirow[t]{3}{*}{1112.5} & \multirow[t]{3}{*}{1044.3} & 993.7 \\
\hline & & & $1419.5^{*}$ & & 2948.0 & 1228.6 & & & 922.7 \\
\hline & & & & & 2889.9 & 1213.0 & & & \\
\hline & \multirow{3}{*}{ Intensity } & 0.0002 & 0.0031 & \multirow[t]{3}{*}{0.0026} & 0.0013 & 0.002 & \multirow[t]{3}{*}{0.0076} & \multirow[t]{3}{*}{0.0169} & 0.0059 \\
\hline & & & 0.0039 & & 0.0041 & & & & 0.0032 \\
\hline & & & & & 0.0038 & & & & \\
\hline
\end{tabular}

*Indicates band splitting. 


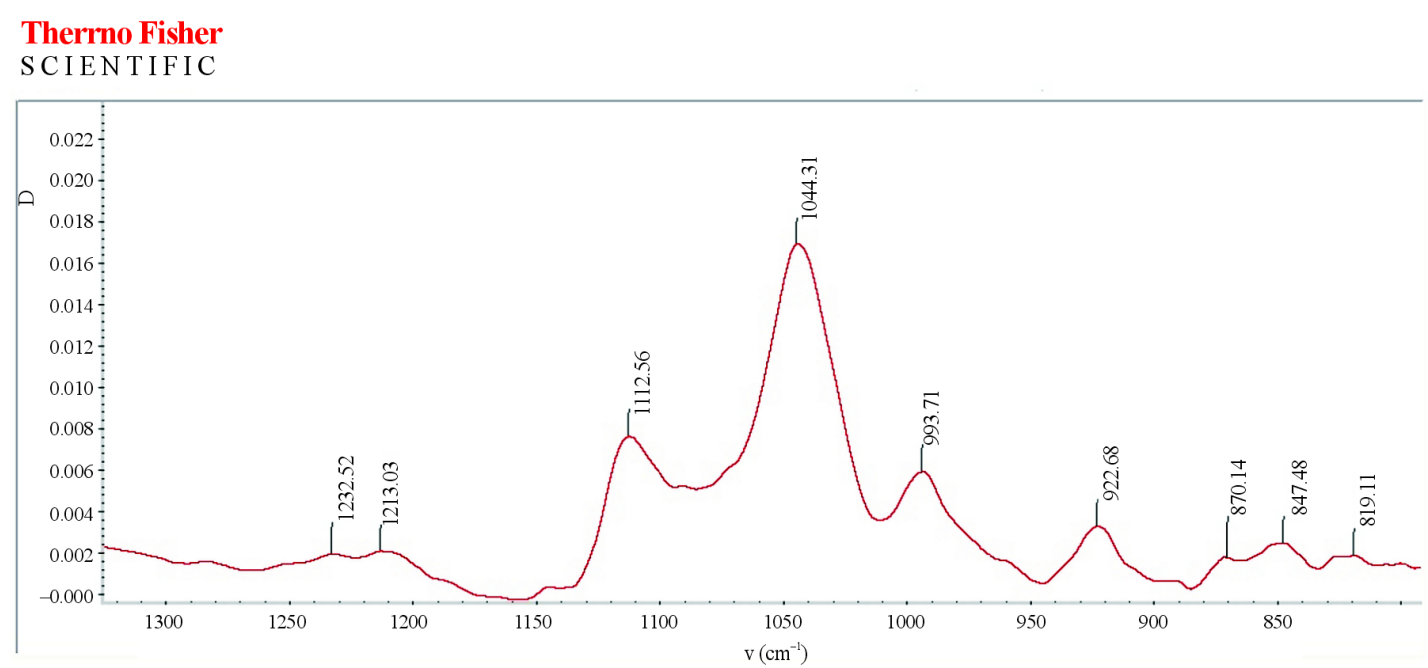

(a)

Therrno Fisher

S CIENTIFIC

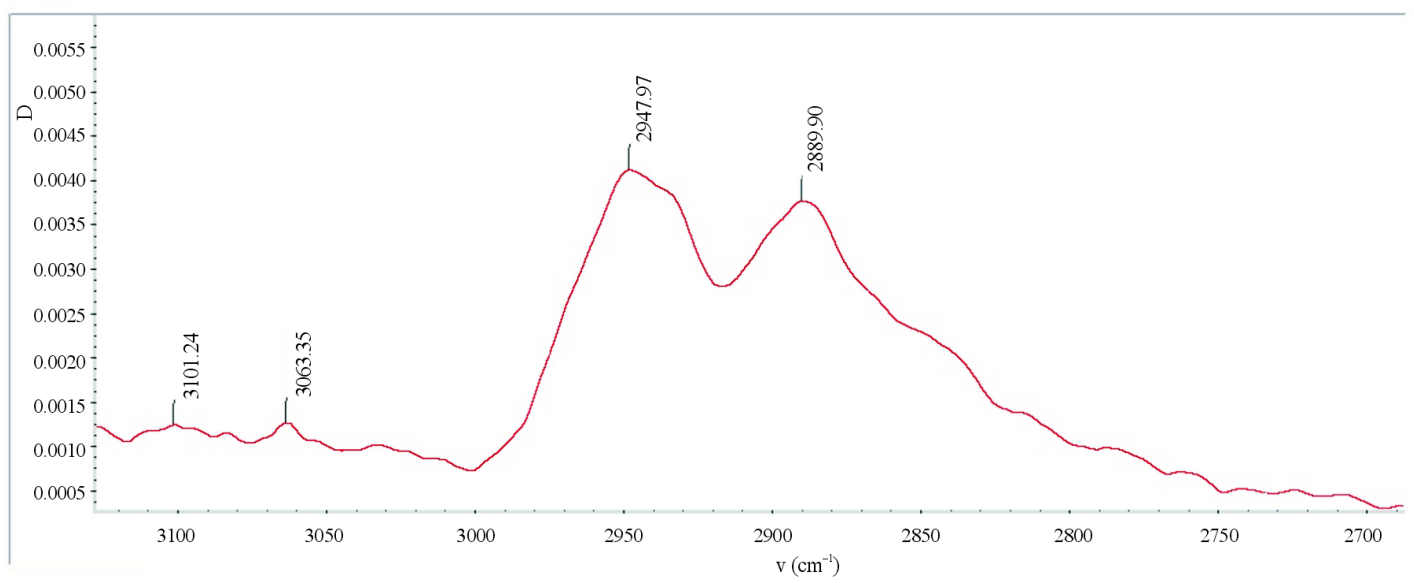

(b)

Figure 2. (a) FTIR spectra of duplm: $\left(\mathrm{C}_{\text {tris-HClbuf }}=0.01 \mathrm{M}, \mathrm{pH} 7.4\right) ; v=800-1300 \mathrm{~cm}^{-1}$; (b) FTIR spectra of duplm: $\left(\mathrm{C}_{\text {tris-HClbuf }}=0.01 \mathrm{M}, \mathrm{pH} 7,4\right) ; v=2700-3100 \mathrm{~cm}^{-1}$.

the $\mathrm{CH}$ bonds show up as the absorption bands at 1418.58 and $1453.88 \mathrm{~cm}^{-1}$. Whereas in duplm_23 these bands (1419.50 and $1459.24 \mathrm{~cm}^{-1}$ ) are split. In addition, quite intense absorption bands at 993.71 and $922.68 \mathrm{~cm}^{-1}($ the CC skeletal vibrations) are recorded in duplm_23 (Figure 1 and Figure 2), while in dupl_23 these bands are absent; note that the band at $922.68 \mathrm{~cm}^{-1}$ is assigned to the $\mathrm{Z}$ conformation.

CH stretching vibrations. Analysis of the spectra in the short-wave region revealed the presence of some absorption bands for dupl_23, in particular, 3076.47, 2979.64, 2944.32 and $2901.99 \mathrm{~cm}^{-1}$. The bands at 3063.35, 2947.97, 2936.13 and $2889.90 \mathrm{~cm}^{-1}$ were recorded for duplm_23 (Figure 1(b) and Figure 2(b)). It is seen that all the absorption bands in duplm_23 are shifted with respect to same bands indupl_23; the band at 2979.64 is shifted by $32.33 \mathrm{~cm}^{-1}$ to the long-wave region. This substantial shift can be attributed to an increased ordering of bases and monosaccharides and stronger Van der Waals forces between them.

Thus, the analysis of IR Fourier spectra of dupl_23 and duplm_23 showed that their conformations differ, duplm having a more ordered structure than the duplex. This is indicated by the frequency shift in the backbone and $\mathrm{CH}$ bonds region as well as by changes in the ratios of the absorption bands corresponding to the backbone and changes in intensity of the bands corresponding to $\mathrm{CH}$ stretching vibrations. Changes in the integrated intensity ratio $S_{1044} / S_{1085}$ for duplm testifies to the order $\rightarrow$ order structural transition that occurs due to methylation of the duplex. 
Table 2. Absoption bands which correspond Z-structure [6].

\begin{tabular}{cccccccccc}
\hline No & Compound & $\begin{array}{c}\mathrm{CO}_{\mathrm{b}} \\
{\left[\mathrm{cm}^{-1}\right]}\end{array}$ & $\begin{array}{c}\mathrm{CH}_{3} \\
{\left[\mathrm{~cm}^{-1}\right]}\end{array}$ & $\begin{array}{c}\mathrm{PO}_{2 \mathrm{as}} \\
{\left[\mathrm{cm}^{-1}\right]}\end{array}$ & $\begin{array}{c}\mathrm{PO}_{2 \mathrm{~s}} \\
{\left[\mathrm{~cm}^{-1}\right]}\end{array}$ & $\begin{array}{c}\mathrm{C}-\mathrm{O}-\mathrm{C}_{\mathrm{d}} \\
{\left[\mathrm{cm}^{-1}\right]}\end{array}$ & $\begin{array}{c}\mathrm{C}-\mathrm{C}_{\mathrm{d}} \\
{\left[\mathrm{cm}^{-1}\right]}\end{array}$ & $\begin{array}{c}\mathrm{C}=\mathrm{N} \\
{\left[\mathrm{cm}^{-1}\right]}\end{array}$ & $\begin{array}{c}\mathrm{CH}_{\mathrm{d}} \\
{\left[\mathrm{cm}^{-1}\right]}\end{array}$ \\
\hline 1 & Duplm & 1712.8 & 1337.2 & 1213.0 & 1112.6 & 1044.3 & 922.7 & 1504.6 & 1407 \\
2 & 1636.0 & Dupl & - & - & - & - & + & - & - \\
\hline
\end{tabular}

\section{Discussion}

The study of dupl and duplm demonstrated that the integrated intensity ratio of the absorption bands $\mathrm{S}_{1044} / \mathrm{S}_{1085}$ was equal to 4.4 in dupl and 2.8 in duplm. This 1.5-fold difference indicates that integrated intensity of the absorption band at $1085 \mathrm{~cm}^{-1}$ strongly decreases after methylation of the duplex. The band at $1085 \mathrm{~cm}^{-1}$ belongs to the $\mathrm{PO}_{2}^{-}$group (symmetric vibrations).

$$
\Delta I=\partial^{2} \mu / \partial q^{2}
$$

where $\mu$ is the dipole moment and $q$ is the generalized coordinate. As follows from this expression, the dipole moment of the $\mathrm{PO}_{2}^{-}$group decreases, i.e. the duplex becomes more hydrophobic after the methylation. In addition, the duplm backbone is described by a quartet (the absorption bands at 1112, 1083, 1043 and 994.5), and the dupl backbone is described by a triplet $\left(1085,1044.4\right.$ and $\left.1001.3 \mathrm{~cm}^{-1}\right)$. What is the reason for decreasing the dipole moment in the phosphate group? In our opinion, this is related to manifestation of the electron-donor properties of methylated bases as a result of hyperconjugation [11], which leads to partial neutralization of the positive charge of phosphorus atom and enhances the hydrophobic properties of duplm.

Essential changes occur also in the region of $\mathrm{CH}$ stretching vibrations. A quartet (the absorption bands at 2979, 2944, 2918 and $2901 \mathrm{~cm}^{-1}$ ) was observed for dupl, while only two main bands (at 2945.7 and $2888.4 \mathrm{~cm}^{-1}$ ) were seen in this region for duplm. The $2979 \rightarrow 2945.7 \mathrm{~cm}^{-1}$ shift is equal to $33.3 \mathrm{~cm}^{-1}$; this is a pronounced shift that can be interpreted as a structural transition from one conformation to another. The main reason is related to a considerable ordering of bases, formation of the energetically more favorable conformation of deoxyribose, and their spatial ordering with respect to the duplex axis, which produces changes in the backbone structure, in particular, the endo $2 \rightarrow$ endo 3 conformational changes of deoxyribose. Exactly these conformations radically change the structure of DNA backbone [13] [14]. We think that after methylation of the duplex, individual bases become highly cooperative and form a joint "rigid block".

It should be noted that methylation is accompanied by the order $\rightarrow$ order structural transition and, in particular, by the $\mathrm{B} \rightarrow \mathrm{Z}$ transition. Methylation induces conformational changes and decreases enthalpy of the transition [5]. Thus, we think that the changes observed in the region of backbone and $\mathrm{CH}$ stretching vibrations are caused by the $\mathrm{B} \rightarrow \mathrm{Z}$ transition. This is indicated also by the absorption bands revealed in methylated duplexes, which correspond to the $\mathrm{Z}$ structure (Table 2).

\section{References}

[1] Dyachenko, O.V., Shevchyk, T.V. and Buryanov, Y.I. (2010) Structural and Functional Features of the 5-Methylcytosine Distribution in the Eukaryotic Genome. Molecular Biology, 44, 171-185. http://dx.doi.org/10.1134/S0026893310020019

[2] Klenov, M.S. and Gvozdev, V.A. (2005) Heterochromatin Formation: Role of Short RNAs and DNA Methylation. Biochemistry (Moscow), 70, 1187-1198. http://dx.doi.org/10.1007/s10541-005-0247-4

[3] Vanyushin, B.F. (2007) A View of an Elemental Naturalist at the DNA World (Base Composition, Sequences, Methylation). Biochemistry (Moscow), 72, 1289-1298. http://dx.doi.org/10.1134/S0006297907120036

[4] Banyay, M. and Graslund, A. (2002) Structural Effects of Cytosine Methylation on DNA Sugar Pucker Studied by FTIR. Journal of Molecular Biology, 324, 667-676. http://dx.doi.org/10.1016/S0022-2836(02)01104-X

[5] Temiz, N.A., Donohue, D.E., Bacolla, A., Luke, B.T. and Collins, J.R. (2012) Role of Methylation in the Intrinsic Dynamics of B and Z-DNA. PLoS One, 7, e35558. http://dx.doi.org/10.1371/journal.pone.0035558

[6] Rauch, C., Pichler, A., Trieb, M., Wellensohn, B., Liedt, K.R. and Mayer, E. (2005) Z-DNA’s Conformer Substrates Revealed by FT-IR Difference Spectroscopy of Nonoriented Left-Handed Double Helical Poly (dG-dC). Journal of Biomolecular Structure and Dynamics, 22, 595-614. http://dx.doi.org/10.1080/07391102.2005.10507029 
[7] Panin, L.E., Kunitsyn, V.G. and Tusikov, F.V. (2005) Effect of Glucocorticoids and Their Complexes with Apolipoprotein A-I on the Secondary Structure of Eukaryotic DNA. International Journal of Quantum Chemistry, 101, 450467. http://dx.doi.org/10.1002/qua.20200

[8] Panin, L.E., Kunitsyn, V.G. and Tuzikov, F.V. (2006) Changes in the Secondary Structure of Highly Polymeric DNA and CC(GCC) $)_{\mathrm{n}}$-Type Oligonucleotides under the Action of Steroid Hormones and Their Complexes with Apolipoprotein A-I. Journal of Physical Chemistry B, 110, 13560-13571. http://dx.doi.org/10.1021/jp068011n

[9] Panin, L.E. and Kunitsyn, V.G. (2009) The Initiation Mechanism of Gene Expression in Ascitic Hepatoma Cells under the Action of Dehydroepiandrosterone in a Complex with Apolipoprotein A-I. Current Chemical Biology, 3, 306-314.

[10] Chmuzh, E.V., Kashirina, Yu.G., Tomilova, Yu.E., Chernukhin, V.A., Okhapkina, S.S., Gonchar, D.A., Dedkov, V.S., Abdurashitov, M.A. and Degtyarev, S.H. (2007) Gene Cloning, Comparative Analysis of the Protein Structures from Fsp4HI Restriction-Modification System and Biochemical Characterization of the Recombinant DNA Methyltransferase M. Fsp4HI. Molecular Biology, 41, 43-50. http://dx.doi.org/10.1134/S0026893307010062

[11] Ingold, K. (1973) Theoretical Bases of Organic Chemistry. Nauka, Moscow.

[12] Smith, A. (1980) Applied Spectroscopy. Mir, Moscow.

[13] Ovchinnikov, Yu.A. (1987) Bioorganic Chemistry. Nauka, Moscow.

[14] Rubin, B.A. (1990) Biophysics. Vyschaya Shkola. 